\title{
Wilder Penfield and the Montreal Neurological Institute: Heralding the Modern Age of Neurology and Neurosurgery
}

\author{
Alexandre Henri-Bhargava* B.Sc.
}

The Montreal Neurological Institute (MNI) was founded in 1934 as an institute "dedicated to relief of sickness and pain and to the study of Neurology", as is inscribed on a plaque adorning its exterior (1). To its founder, Dr. Wilder Penfield, "The problem of neurology is to understand man himself" (2). Thus this institute was not only founded to treat and study human sickness through medicine, but to understand humankind and the human mind in health, through science. How did it come to be that an institute with such a seemingly lofty purpose came to be founded in Montreal? What was its place in the larger picture of medicine at the time? The MNI is now a well-known institute, but what were its initial contributions to science, medicine, and the general public?

$$
* * * * *
$$

To understand what shaped the founding of the MNI, one first must understand what shaped its founder, Wilder Graves Penfield (1891-1976). He is described by Dr. William Feindel, his friend and later the third director of the MNI, as "having a great vision in life" (3). He acquired this vision foremost from his mother, who was convinced that her son was destined for greatness. As a student, Wilder shared his mother's belief. While studying at Princeton University, he sat down one day to make a list of possible careers in the hopes of choosing one that would fit the following criterion: "Objective: to support myself and family and somehow make the world a better place in which to live" (4). Lofty as the latter objective might seem, the

* To whom correspondence should be addressed: alexandre.henri-bhargava@mail.mcgill.ca young Penfield was determined to fulfill it. As a student at Oxford University during World War I, he was to travel to the continent to work in a field hospital. His ship was torpedoed during the crossing, and he feared that he might drown. Yet, he refused to die because he simply believed that, "This cannot be the end. My work in the world has only just begun. This cannot be the end" (4).

At this age, Wilder Penfield was not only obviously driven but also impressionable. Years later, his beliefs about students in general would reveal his own feelings about himself as a student; "[Students] are lonely and highly impressionable and they have almost always some hidden strength" (5). The young Penfield took his own first impressions from Edward Conklin, his biology professor during his undergraduate years at Princeton. Conklin's passionate teaching of the subject led to Penfield's initial interest in medicine. Next, he would be inspired and impressed by two very renowned professors he met at Oxford, Sir Charles Sherrington and Sir William Osler. Feindel states that "Charles Sherrington became his scientific hero and William Osler his life-long inspirational tool" (6). Penfield was immediately impressed with Sherrington, who had contributed a vast amount of scientific knowledge in his investigation of reflexes, and it was Sherrington who inspired Penfield to study neurology. Of this, Penfield wrote that:

\footnotetext{
I looked through his eyes and came to realize that here in the nervous system was the great unexplored field - the undiscovered country in which the mystery of the mind of man might someday be explained (5).
}

After his studies at Oxford, Penfield obtained his 
medical degree in 1918 at the Johns Hopkins University in Baltimore, whose medical school had been founded in part by his other Oxford hero, Sir William Osler. After this, Dr. Penfield spent a year following his burgeoning interest in neurology, interning at the Peter Bent Brigham Hospital, Boston, where he had a chance to closely observe the operations of Dr. Harvey Cushing, arguably the best neurosurgeon in the world at the time, and one whose fame was bringing respectability to the still-young field (4). He went on to do further study at the National Hospital, Queen's Square, London, where Victor Horsley had essentially 'founded' British neurosurgery. There he studied with the neuropathologist Gordon Holmes (who would eventually be knighted for his discoveries) and it is there that Dr. Penfield realized that he was living in a time when "advance in knowledge of anatomy and physiology of the brain was rapid, and neurologists were beginning to apply the new understanding to brain disease" (5).

With this in mind, Penfield returned to America, in 1922, and began work as a neurosurgeon at the Presbyterian Hospital of Columbia University in New York. By now he was ready to tackle an important question that came to him one day from a senior colleague, Prof. Bill Clarke; "What causes epilepsy?" Ignorant of, but wanting to know the answer to that fundamental question, he came to see how his broad education had moulded him. He realized that:

\begin{abstract}
A brain surgeon was not different from those who operated on other parts of the body. He too should study the healing process of the organ he treats. But no one had done it, as far as I was aware (5).
\end{abstract}

This led him on a new quest to try to study the brain and its healing process as a whole. Along the way, he 'acquired' an assistant, Dr. William Vernon Cone who was to become his life-long partner in the effort.

Adopting a new method was difficult for Penfield because it required him to delve into all aspects of studying the brain: the basic sciences of pathology, physiology, cytology, and anatomy would be critical to his approach to clinical neurosurgery. He would have to become the type of neurosurgeon that his hero Osler had advocated when he had said that he:

\footnotetext{
...would prefer to see neurology a special department, so that there would not be neurological physicians and surgeons, but medical chirurgical neurologists, properly trained in the anatomical, physiological, clinical and surgical aspects of the subject (7).
}

This would require him to keep up to date in and integrate all of these fields. Yet this was an era before the internet and long distance phone plans. Keeping up to date with research that was taking place far away was not necessarily easy. Thus, by 1922, Dr. Penfield "was firmly of the opinion that 'the real future of neurology' called for a neurological institute in which neurology and neurosurgery were not to be divided" (5). Moreover, as William Feindel relates, "Penfield had the increasing conviction that it would be best to bring together under one roof neurology, neurosurgery, neuropathology and neurophysiology" (8).

Thus, by 1928 Dr. Penfield's vision was established: He wished to study the human nervous system in order to learn how to treat it and in order to begin to understand the human mind. This vision was the result of the unique experience of having studied with a plethora of great teachers and scientists. Later, Penfield would acknowledge this by saying:

I who thought himself the neurosurgical pupil of no one in particular, was, in reality, the pupil of everyone. I was a jack-of-all-trades and I had plans that would make me a jack-of-further-skills that I would need in the years ahead (5).

$$
* * * * *
$$

Dr. Penfield, therefore, had a plan and he had ambition; but he needed a setting in which to execute this plan, and more importantly, he needed like-minded persons to share it with. One such person was Edward Archibald, the professor of surgery at McGill University in Montreal, Canada. Prof. Archibald had long had an interest in neurology and neurosurgery and he had studied at Queen's Square with Victor Horsley. By 1927, however, he had divided his research and work in other areas and he realized that Montreal needed a full-time neurosurgeon. Thus, he recruited Penfield to take over and expand his neurosurgical duties in Montreal at the Royal Victoria Hospital $(\mathrm{RVH})$. He immediately recognized that Penfield "[had] very large plans, plans for much more than I had in mind" (5). Penfield had already established a Laboratory of Neurocytology in New York with Dr. Cone as his assistant, and thus, were he to move to Montreal, he would want to establish and expand a similar research laboratory to coincide with his practice there. Archibald was receptive to Penfield's plans because he was also a researcher, like Penfield. William Feindel writes that, "W.E. Gallie, Professor of Surgery at Toronto, credited Archibald with changing the character of surgical education in Canada from purely clinical to scientific" (9).

Thus, Penfield transplanted his research and practice 
from New York to Montreal, where he now had some allies who began to share his idea - of working to advance medical knowledge, unhampered by any "artificial" division between basic and clinical science, or between medicine and surgery. Someone who obviously shared this vision was Dr. Cone, who came to Montreal with Penfield. Until the end of his life, Bill Cone would remain Penfield's friend and partner. Somewhat whimsically, Penfield realized, in retrospect, that Cone and he "...were the beginning of a team, something more considerable than any individual can be.... We had heard together, the everlasting whisper that experienced explorers hear... we were fellow explorers" (5). With additional partners sharing his dream in Montreal, Penfield decided to make this "everlasting whisper" into a concrete plan: a proposal to the Rockefeller Foundation, a philanthropic organization dedicated to the advancement of medical science, for the building of an institute such as the one he had first envisioned some seven years earlier. About this, William Feindel writes that:

The excellent relationship that McGill University had already developed with the Rockefeller foundation since 1922 to modernize its medical school offered Penfield a favourable matrix in which he could fulfill his conviction to "provide a center for neurological thought that would serve the whole continent..." (6).

However, Penfield did not take full advantage of this "excellent relationship" and five months after having arrived in Montreal, he went alone to Richard Pearce, in charge of medical grants at the Rockefeller Foundation, with his idea. Although it was supported in principle by Archibald and by Charles Martin, the Dean of McGill's Faculty of Medicine, the application was denied.

The MNI was Dr. Penfield's brainchild. He sowed the "germinal idea" as he termed it*. But in order for it to become a reality, he had to wait for this germinal idea to sprout and take firm roots in other like-minded thinkers. A key person who also came to adopt the idea was Alan Gregg, the man who replaced Pearce at the Rockefeller Foundation. Gregg was himself a physician by training and had grown very interested in the nervous system as a result of having read Osler's Principles and Practice of Medicine. By the time Penfield went to Gregg to follow up on McGill's request, Gregg had already decided that the Rockefeller Foundation should support neurological research. In fact, he was also considering other proposals for funding a neurological institute. Luckily for Penfield, he made a great impression on Gregg and the two men realized that they had similar visions. Gregg said of Penfield's plan, "I think I understand what you want to do. You have a plan that gives real promise in a field that is calling desperately for exploration" (5). In April 1932, the Rockefeller Foundation awarded McGill University a grant of $\$ 1$ 232000 for the creation of a neurological institute. Two hundred and thirty-two thousand dollars was to contribute to half the cost of building the institute, and $\$ 1000000$ was to establish a permanent endowment for the scientific research to be carried out there.

$$
* * * * *
$$

Why Montreal? There were many factors that made McGill University and Montreal an ideal setting in which to build the institute. First was the support that McGill had shown to Penfield. This support extended equally to the neurologists of Montreal with whom Penfield had obviously made friends, including Colin Russel, McGill's Professor of Neurology who would become the first neurologist on staff at the MNI. The close association of McGill's new Department of Neurology and Neurosurgery with the RVH would ensure that the RVH, McGill, and the yet-to-be MNI could all function in close association with each other, sharing resources, and more importantly, ideas. To illustrate this point, Gordon Holmes made the following comment in his Foundation Lecture for the MNI:

The proximity of this Institute to the medical and surgical wards of the Royal Victoria Hospital, and the connexion of its staff with other institutions in your city, will, I have no doubt... provide the desirable opportunity for intellectual and practical intercourse with mutual benefit (1).

In spite of this, it seemed remarkable to some that an American philanthropy would award such a large grant to create a Canadian institute; But this action was defended by many valid arguments. One was that the institute was to be a scientific institute that would perform research without boundaries. A second was the fact that both the Montreal public and the Montreal medical community were very enthusiastic about the prospects of building such an institute and were prepared to support it. The Americans recognized and appreciated these facts. An editorial in the New York Times of April 21, 1932 on "Illocality" aptly illustrates these and other arguments supporting the grant. It reads:

[McGill University's] reputation and administrative efficiency were also an element in the decision. Besides, ...the citizens of Montreal showed interest and enterprise in welcoming such a foundation... [The institute's] benefits will have no geographical boundaries... Fortunately for Canada, there was no tariff against such talents as DR. PENFIELD carried over the border, and fortunately, no 
duties can be laid against the results of the researches of the institute (10).

These events were taking place before the age of biotechnology companies and squabbles over intellectual property rights, and financial gain was no where mentioned as a desired outcome of the institute. Thus, the Americans believed that everyone, everywhere, could stand to benefit from the research that the institute would carry out.

Dr. Penfield also believed this and he saw Montreal as the place where medical discoveries could be most rapidly disseminated, and where one could also be receptive to the greatest amount of beneficial external influences. He expressed this by writing that:

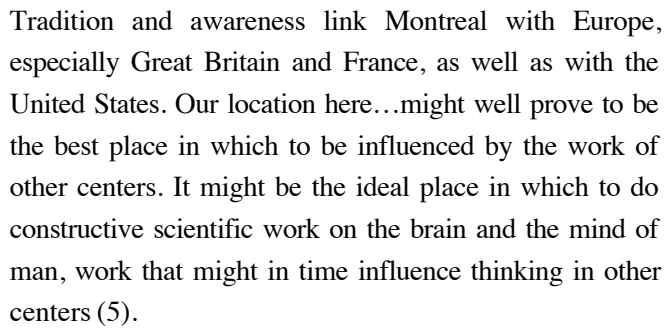

In this quotation, Penfield also alluded to the fact that one of Montreal's great strengths was its mix of two different, but equally vibrant cultures. The mix of French and English was an asset because it meant that while many institutions in Montreal were set up in parallel, they did not necessarily mimic each other. This was true of Montreal medical and educational institutions. From his very first days in Montreal, Penfield had striven to initiate a dialogue with the French-Canadian neurologists and by doing so he doubled the amount of information and personnel to which the English ones had access. Montreal was unique in providing such a setting and it would be of immense benefit to the prospects of a new institute if people and knowledge from both cultures were incorporated into the institution.

There were further reasons why 1930's Montreal was an ideal city for such a venture as was being proposed. Depression or not, Montreal was a comparatively large and wealthy city. In such a city it would be possible to raise private funds for the institute. Many of the wealthy so-called 'Scottish merchant princes' were already benefactors of McGill University, and funds for the remainder of the building were solicited from them. As is recounted in the Foundation Volume of the Hospital, "The vestibule [of the institute] bears the plaque of acknowledgement to generous benefactors: Rockefeller Foundation, Province of Quebec, City of Montreal, Sir Herbert Holt, J.W. McConnell, Walter Stewart, Four anonymous donors" (1). The three named individual benefactors had assured sizable donations that would cover the costs of the half of the edifice not covered in the Rockefeller grant. J. W. McConnell should be singled out in, particular. He was a media baron who published the aforementioned Montreal Star. He was an ardent supporter of McGill University and the new MNI, and would continue to provide needed money even after his initial generous donation of $\$ 100000 \dagger$.

Notable as well, was the support that the MNI received from the public sector. As the institute's research and hospital portions were to have independent budgets, both of which were not to draw on McGill's general budget, the hospital operations would also have to be funded. For this, Principal Currie and Dean Martin approached the provincial and city governments and obtained \$20 000 per year from the Province of Quebec and $\$ 15000$ per year from the City of Montreal.

$$
* * * * *
$$

On September 9, 1934, the Montreal Neurological Institute was officially opened by Edward W. Beatty, K.C., Chancellor of McGill University. An article that appeared that day in the Montreal Gazette ran a headline that described the event as an "Epoch Making Function" and proceeded to state that the cornerstone was laid "in the presence of a distinguished gathering of leading figures in the educational, ecclesiastical, medical, business and civic life of Montreal" (11). Luckily for the MNI, 'good things' came from the beginning. Dr. Penfield, accompanied by Dr. Cone and those studying with them, achieved great success in neurosurgery. Penfield's knowledge of the anatomy, physiology, and pathology of the brain, in addition to his beginning to understand the ætiology of the diseases he was working on as a result of his research, led him to strike out in new directions, attempting procedures few others had before. In particular, he made remarkable improvements in curative surgery for epilepsy.

Dr. Penfield's patients appreciated how his research was enabling his clinical work. In the early case of one William Ottmann, a private patient, Penfield had cured him of debilitating seizures. This had been a particularly difficult case and Penfield had called in many experts from near and far to assist him with a novel procedure, at Ottmann's mother's expense. A very grateful Mrs. Ottmann was overjoyed and before her death a short time later, she donated $\$ 50000$ to Penfield's research, which eventually went into building the MNI. Penfield's success in treating William Ottmann came to be repeated many times at the MNI. It is not surprising, then, that quite quickly, "the institute had become the number one center for neurology and neurosurgery in 
Canada" (12).

In the new institute, Dr. Penfield's operations began to make headlines across the country. During his operations, he would map out the brain of his patients to locate the origin of their seizures. In doing so, Penfield was able to develop maps of the human brain, including his famous homunculus. Penfield compiled these early findings at the MNI into a monograph in 1941 (13) and another in 1954 (14).

$$
* * * * *
$$

'Good things' also came to the hospital portion of the MNI. This was, in fact where the public could feel the direct impact of the MNI's foundation. Patients of the MNI in its early days were well attended to by a caring staff. A large part of this was due to the influence of Dr. Bill Cone, who had become the institute's first Neurosurgeon-in-Chief. Of Cone, Preston Robb writes that:

\footnotetext{
With the passage of time, he gave up neuropathology and devoted all his time to patient care. He developed new neurosurgical techniques and better ways of getting the patients to the hospital and looking after them when they were there.... The great neurosurgical reputation of the Neuro were largely due to the many innovations of Bill Cone (12).
}

Cone's innovation is described by Mary Fitzgerald, a nurse at the MNI during the early years; "He brought back ideas for equipment from all of his experiences elsewhere. For instance, the headrest with its multiple uses was his invention and of course the Cone-Barton tongs" (15). She also echoes Robb in saying that the high quality of patient care at the MNI was due to Cone, writing that, "Dr. Cone was the surgeon that showed his interest in nursing care and ways to improve it" (15). Elizabeth Barrowman, another early nurse goes on to further discuss Cone's many inventions and innovations, including the rocking 'Neuro' bed, drill hole techniques for the relieving of intracranial pressure, a wrinkle-free lining for the Minerva jacket (a sort of half-body cast immobilizing the head and neck), an improved neck collar, and the 'Pancake Turner' for prevention of bed sores, amongst many others, such as the helicopter ambulance (which would land on the turf of the Molson Stadium adjacent to the MNI) (15).

$$
* * * * *
$$

In developing for himself the model of how medicine should be, Dr. Penfield dreamed of creating the MNI. This happened not because Penfield was either a genius or a visionary, but simply because he was a product of his environment, and he was ambitious and observant enough that he 'caught on' to the fact that neurology was entering what Robert Aird calls its expansive "flowering phase," which would be heavily dependent upon the integration of the clinical and basic sciences (16).

Along the way, many others who were of similar mind began to share Penfield's dream. Thus, a favourable intellectual environment for the development of the MNI presented itself. Some of the like-minded thinkers, especially Alan Gregg, were in the possession of money, and they deemed this particular idea to be the right one in which to invest that money. Thus, a favourable financial setting for the development of the MNI presented itself. McGill University and the people of Montreal were receptive to the ideas that Penfield and his associates presented to them. Governments donated to the hospital budget of the institute. McGill had begun a period of modernizing its medical faculty, recently having built a new pathology institute and a new biology building. It was eager to adopt a modern new medical institute. Montreal also seemed to be the ideal facility for many of the reasons that were discussed earlier. Thus, the right location for the development of the MNI presented itself. The confluence of these factors was well-timed enough so that the institute became a reality. One could as easily argue that this was fate as one could argue that it was chance. These arguments are rendered moot when one looks at the 'big picture'; That is, that the MNI came into being because current progress in medicine, and specifically in neurology, had found in science a useful tool. In a sense, neurology and neurosurgery were becoming "the neurosciences" and adopting the biomedical paradigm. Moreover, science could no longer be performed by mere individuals, but the scope of neurological research and care had now to be expanded within an institute.

$$
* * * * *
$$

The early years of the MNI definitely resulted in an improvement "to relief of sickness and pain". For example, Head Nurse Eileen Flanagan did much to ensure a high calibre of nurses right at the onset of the MNI's existence. The significance of this, in the 'big picture,' is that:

\footnotetext{
...those [nurses] who took the Post Basic Program have gone away enriched and enthused by the nursing techniques they have learned. They have spread their knowledge across Canada, the United States and abroad. The most significant thing they have done is to improve the nursing care of the neurologically disabled around the world (15).
} 
Moreover, the scientific research at the hospital yielded some results that were directly applicable to patient care. For example, Herbert Jasper recounted the story of:

Sam... a young 8 year old with seizures.... He was the first patient to be operated upon by Dr. Penfield with the aid or preoperative EEG localization and corticography during the procedure. His seizures were controlled and his behaviour problem eventually improved after his anticonvulsant medication was reduced. Forty-five years later... we were surprised to see a distinguished looking gentleman.... It was Sam (17).

As exemplified by this anecdote, the founding of the MNI saw an increase in quality of life for neurological patients. The early years justified the foundation of the MNI with regards to improvement in patient care and quality of life.

As far as "the study of neurology" is concerned, the MNI represented a microcosm of the modern paradigm of medicine, and as Aird states, "in the Penfield account, a noteworthy fact is that the studies on epilepsy, like the studies of [several others], strikingly exemplify the dependence of modern neurology on... scientific advances" (16). The significance of the early days of the MNI is that it used this dependence to its advantage and was thus able to help start an age of modern progress in neurology.

\section{$* * * * *$}

Preston Robb writes that "Wilder Penfield had a dream, and he saw his dream fulfilled" (18). Penfield was a driven and dedicated surgeon, scientist and philosopher. This helped him fulfill his dream of building the Montreal Neurological Institute. But this dream was shared by others. It has been argued here that the fulfillment of this dream was a sign of his times, of faith in "biomedicine" and in moving beyond the descriptive phase of neurology. It was also a confirmation of this faith that the dream bore the fruit which was anticipated -- that is, that the MNI had early medical and scientific successes. Thus, Wilder Penfield and the MNI helped to herald the modern age of neurology.

\section{ACKNOWLEDGMENTS}

This article is a significantly abridged version of an essay that won the 2002 Roland MacKay Award from the American Academy of Neurology. The original essay is dedicated to the memory of Dr. Donald Bates, Cotton-Hannah Professor of the History of Medicine at McGill University. He first piqued the author's interest in the history of medicine, and sadly passed away in the summer of 2001. He was a gentle, dedicated, and thoughtful scholar, and an inspiring teacher who will be dearly missed.

\section{REFERENCES}

1. Montreal Neurological Institute. Neurological Biographies and Addresses: Foundation Volume (Published for the Staff, to Commemorate the Opening of the Montreal Neurological Institute, of McGill University). London, UK: Oxford University Press, 1936.

2. Feindel W. To Praise an Absent Friend. CMA Journal 116:13651367; 1977.

3. Lower, Rob, director. Something Hidden: A Portrait of Wilder Penfield. [Video recording] Produced by Rob Lower, Michael Scott and Vincent Tovell. National Film Board of Canada, 1987.

4. Lewis J. Something Hidden: A Biography of Wilder Penfield. Toronto: Doubleday, 1981.

5. Penfield W. No Man Alone: A Neurosurgeon's Life. Toronto: Little, Brown, 1977.

6. Feindel W. The Montreal Neurological Institute. Journal of Neurosurgery 75:821-822; 1991.

7. Osler W. Discussion: British Medical Association Meeting. Lancet 2:334; 1907. Quoted in Feindel W. Neurosurgery at the Montreal Neurological Institute and McGill University Hospitals. Neurosurgery 39:831; 1996.

8. Feindel W. The Contributions of Wilder Penfield and the Montreal Neurological Institute to Canadian Neurosciences. In: Roland CG, editor. Health, Disease and Medicine: Essays in Canadian History (Proceedings of the First Hannah Conference on the History of Medicine, McMaster University June 3-5, 1992). Toronto: Clarke Irwin, 1993.

9. Feindel W. Neurosurgery at the Montreal Neurological Institute and McGill University Hospitals. Neurosurgery 39:830-839; 1996.

10. Illocality. New York Times. 21 April, 1932: 20.

11. Lord Bessborough Lays Cornerstone of Neurology Unit. The Gazette. Montreal, 7 October, 1933.

12. Robb JP. The Development of Neurology at McGill. (Gift of Donald J. Baxter.) Montreal: Osler Library, McGill University, 1989.

13. Penfield W and Erickson TC. Epilepsy and Cerebral Localization. Springfield, MA: Charles Thomas, 1941.

14. Penfield W and Jasper, HH. Epilepsy and the Functional Anatomy of the Human Brain. Boston, MA: Little, Brown, 1954.

15. Robertson CE, editor. Nursing Highlights: Montreal Neurological Institute \& Hospital (1934-1990). Brockville, Ont.: Henderson Printing, 1992.

16. Aird RB. Foundations of Modern Neurology: A Century of Progress. New York, NY: Raven Press, 1994.

17. Jasper HH. The Centrencephalic System. CMA Journal 116:1371-1372; 1977.

18. Robb JP. The Institute and Hospital. CMA Journal 116:1368$1369 ; 1977$.

\section{GENERAL REFERENCES}

Bates D. Lectures in Health and the Healer in Western History, McGill University, 1998.

Bell RE. Wilder Penfield: His Legacy to Neurosurgery, Introduction. CMA Journal 116:1365; 1977.

Conrad LI, Neve M, Nutton V, Porter R, and Wear A. The Western Medical Tradition: $800 \mathrm{BC}$ to $\mathrm{AD} 1800$. Cambridge, UK: 
Cambridge University Press, 1995.

Elliott K and Allan C. Neurochemistry. CMA Journal 116:1372-1373 1977

Evans JP. Excited Beginnings. CMA Journal 116:1367; 1977.

Fleming G. The Picture of Health. The Gazette. Montreal: 8 September, 1934.

Hebb D. The Frontal Lobe. CMA Journal 116:1373-1374; 1977.

Kyle RA and Shampo MA. Wilder Penfield - Contributor to the Surgical Treatment of Epilepsy. Mayo Clinic Proceedings 67:596; 1992

McNaughton FL. Impact on Medical Neurology. CMA Journal 116:1370; 1977.

Milner B. Memory Mechanisms. CMA Journal 116:1374-1376; 1977.

Montreal Neurological Institute. Prospect and Retrospect in Neurology: Second Foundation Volume (Published for the Staff, to Commemorate the Opening of the McConnell Wing and the Second Foundation of the Neurological Institute, of McGill University). Toronto: Little, Brown, 1955.

Preul MC and Feindel W. Origins of Wilder Penfield's Surgical Technique. Journal of Neurosurgery 75:812-820; 1991.
Rasmussen, TB. Surgical Treatment of Epilepsy. CMA Journal 116:1369-1370; 1977.

Stevenson L. Novelist and Historian. CMA Journal 116:1376-1377; 1977.

Concentration of Brain Cases Urged. The Gazette. Montreal, 2 June, 1933: 4 .

McGill Will Fly Viceregal Flag. The Gazette. Montreal, 6 October, 1933.

Founder's Day Program Includes Fall Convocation And Laying of Neurology Institute Cornerstone. McGill Daily. Montreal, 6 October, 1933: 1.

Founders of Greater Montreal. Supplemental to Montreal Star. 7 October, 1933: 6.

Earl of Bessborough Lays Cornerstone For Institute. McGill Daily. Montreal, 10 October, 1933: 1, 4.

Medical Building Opening Prepared. The Gazette. Montreal, 8 September, 1934.

The Associated Press. Science Has Failed to Explain Problem of Life, Says Marconi. The Gazette. Montreal, 11 September, 1934: 1.

Neurological Institute Opened Doors Thursday. McGill Daily. Montreal, 1 October, 1934: 1, 7 .

Alexandre Henri-Bhargava holds a B.Sc. degree in immunology and social sciences of medicine, from McGill University in Montreal, Canada. He is currently in his third year of medical school at McGill. 